\title{
Riboflavin Production by Roseoflavin-resistant Strains of Some Bacteria
}

\author{
Kunio Matsui, Hsiu-Chuan Wang, Takako Hirota, \\ Hirokazu Matsukawa, Sabu Kasai, Kunihiro Shinagawa*, ${ }^{*}$ \\ and Shohei OTANI** \\ Division of Biology, Research Institute for Atomic Energy, \\ Osaka City University, Sumiyoshi-ku, Osaka 558, Japan \\ * Osaka Prefectural Institute of Public Health, \\ Higashinari-ku, Osaka 537, Japan \\ **Department of Nutrition, Koshien University, \\ Momijigaoka 10, Takarazuka 665, Japan
}

Received September 8, 1981

\begin{abstract}
Riboflavin(RF)-productivity of reseoflavin(RoF)-resistant strains of Staphylococcus aureus, Bacillus pumilus and Bacillus subtilis was studied. Two of three types of resistant strains of $S$. aureus were shown to produce more RF than the parent strains. Resistant strains of $B$. pumilus were also RF-producing, and one type ( $f p$ ) of the resistant strains from $B$. subtilis HW produced a large amount of RF in the culture medium. The hereditary stability of RF-producing properties of the $f p$ type was also shown.
\end{abstract}

RoF ${ }^{1)}$ i.e., 8-dimethylamino-8-demethyl-Driboflavin $^{2)}$ was isolated by Otani et al. from the culture filtrate of Streptomyces davawensis because of its antibacterial activity against Gram-positive bacteria. From its chemical structure, anti-RF activity was assumed to be the mechanism for the antibacterial activity. It was demonstrated to be the case by Otani, ${ }^{3)}$ and the anti-RF activity by RoF analogs by Kasai et $a .^{4,5)}$ One of the reasons for the clinical uselessness of RoF is the appearance of resistant strains of pathogens. In the course of studying RoF-resistant strains of Staphylococcus aureus, Bacillus pumilus and Bacillus subtilis, the production of a large amount of $\mathrm{RF}$ in the culture media by some of the resistant strains was found. The RFoverproducing strains hitherto obtained are not practically useful because of the lower productivity than Eremothecium ashbyii which is used for producing RF industrially, but there is a possibility of finding strains of higher
RF-productivity. As the RF-producing properties are stable in respect of heredity, if strains showing higher productivity than that of Eremothecium are found, such strains may be useful for producing RF.

\section{MATERIALS AND METHODS}

Flavins. RF was purchased from Wako Pure Chemical Industries, Ltd., and used after recrystallization from $2 \mathrm{~N}$ acetic acid. FMN and FAD were obtained from the same company as RF. RoF was synthesized by the method of Kasai et al. $^{2)}$

Bacteria. S. aureus RIMD 3109012 (NCTC 8530) was obtained from the Research Institure for Microbial Diseases, Osaka University, and B. pumilus IFO 12092 and IFO 3813 from the Institute for Fermentation, Osaka. $B$. subtilis HW (IFO 14132) was isolated in our laboratory from a contaminated plate, and was identified as B. subtilis by the Institute for Fermentation, Osaka.

Culture. The culture medium for $S$. aureus, described in the previous report, ${ }^{4)}$ was used as basal medium. The

${ }^{\dagger}$ Present address: Department of Veterinary Medicine, Faculty of Agriculture, Iwate University, Ueda, Morioka, Iwate 020, Japan.

Abbreviations: RF, D-riboflavin; RoF, roseoflavin. 
culture medium for $B$. pumilus and B. subtilis was prepared by adding $2 \mu \mathrm{g}$ of biotin $/ \mathrm{ml}$ of the basal medium. For using it as a solid medium, $1.5 \%$ agar was added to the liquid medium.

The bacteria were cultured at $37^{\circ} \mathrm{C}$, except $B$. pumilus IFO 12092 , which was cultured at $30^{\circ} \mathrm{C}$. In liquid cultures under shaking, the growth was followed by measuring the absorbance at $620 \mathrm{~nm}$ of the culture broth with a Hitachi spectrophotometer 101 equipped with a test tube-holder. ${ }^{4)}$ The number of viable bacteria was determined by the ordinary dilution method. The culture for chemical identification of flavins was performed under shaking in Sakaguchi flasks containing $100 \mathrm{ml}$ of liquid medium.

Isolation of RoF-resistant strains. In the case of S. aureus and B. pumilus IFO 3813, several millions of bacterial cells were inoculated and cultivated on RoF agar media, and in the case of B. pumilus IFO 12092 and B. subtilis HW, about 10,000 of cells were inoculated and cultivated. Surviving colonies were picked up as resistant strains. The RoF concentration was varied according to the inherent resistance of each parent bacterium, i.e., in the case of $S$. aureus, $2 \mu \mathrm{g} / \mathrm{ml}$; B. pumilus IFO 12092 and IFO 3813, $20 \mu \mathrm{g} / \mathrm{ml}$; and B. subtilis $\mathrm{HW}, 100 \mu \mathrm{g} / \mathrm{ml}$.

Estimation of flavins. The RF in culture broth was assayed by a modification of the lumiflavin fluorescence method. ${ }^{6)}$ The culture broth did not contain RoF which might have disturbed the assay. The fluorescence was measured with a JASCO fluorescence spectrophotometer FP-4 (excitation, $450 \mathrm{~nm}$; emission, $510 \mathrm{~nm}$ ).

A colony on an agar plate was picked up and put into $5.0 \mathrm{ml}$ of culture medium without RoF, and incubated. At the early stationary phase of growth, RF was assayed as follows.

(1) RF in culture broth: After the measurement of turbidity, the culture broth $(5.0 \mathrm{ml})$ was heated at $80^{\circ} \mathrm{C}$ for $30 \mathrm{~min}$, and centrifuged at $14,000 \mathrm{rpm}$ for $20 \mathrm{~min}$ after being cooled. The supernatant $(4.0 \mathrm{ml})$ was used for the assay.

(2) RF in culture filtrate: The culture broth $(5.0 \mathrm{ml})$ was centrifuged as above, and $4.0 \mathrm{ml}$ of the supernatant was used for the assay of RF.

(3) RF in bacterial cells: The precipitate centrifuged down in (2) was washed with saline $(3.0 \mathrm{ml})$, centrifuged, and resuspended in $5.0 \mathrm{ml}$ of saline. The suspension was heated at $80^{\circ} \mathrm{C}$ for $30 \mathrm{~min}$ and centrifuged. RF in $4.0 \mathrm{ml}$ of the supernatant was determined.

The determined RF contents were expressed as the quantity in $1.0 \mathrm{ml}$ of culture broth indicating cell growth $\mathrm{OD}_{620}, 1.0$ by calculation.

Identification of flavin in culture filtrates. A few hundred milliliters of culture broth at the early stationary phase was centrifuged. The supernatant was concentrated in vacuo to a few milliliters in a rotary evaporator. From the concentrate, RF was extracted with phenol and transfer- red to a small volume of water by the method of Crammer. ${ }^{7)}$ The RF was identified by thin layer chromatography using the system of a silica gel plate (Merck's precoated silica gel 60) and isoamyl alcohol-methyl ethyl ketone-acetic acid-water $(40: 40: 7: 13$, by volume), and that of a powdered cellulose plate (Avicel plate) and water saturated with isoamyl alcohol.

Experiments dealing with RF were performed in a dark room in the light of a sodium lamp to avoid photolysis of RF.

\section{RESULTS AND DISCUSSION}

\section{RoF-resistant strains of $S$. aureus}

On the agar medium containing RoF at $2 \mu \mathrm{g} / \mathrm{ml}$, apparently three kinds of resistant colony were observed. The first was a yellow colony ( $y$ type), the second a white colony ( $w$ type), and the third a small colony ( $s$ type). The growth rates of the $y$ and $w$ colonies were nearly the same as that of the parent colony, but that of the $s$ colony was markedly lowthe colony could not be recognized until 3 or 4 days incubation, and its diameter, about $0.2 \mathrm{~mm}$, did not get larger even on further incubation for several days. Moreover, the $s$ type colonies were observed mainly around $y$ type ones and at times around $w$ ones. No RoF plate, in which only the $s$ type grew without any $y$ or $w$ type colonies, was found.

The relation of the frequencies of appearance of $y$ and $w$ type colonies and RoF concentration is shown in Fig. 1. The $w$ type

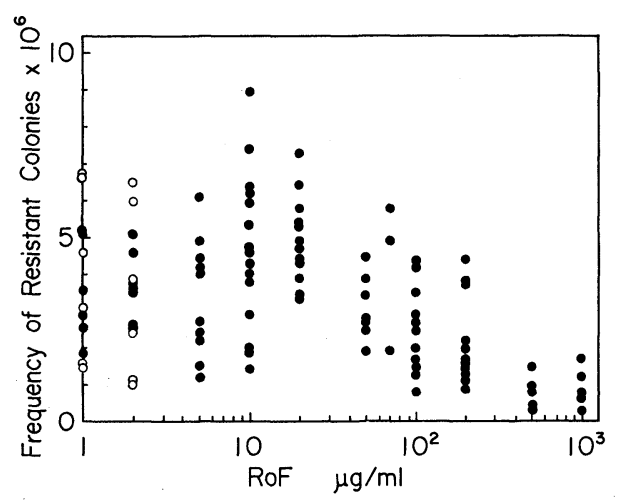

FIG. 1. Frequency of Appearance of $y$ and $w$ Colonies of S. aureus and RoF Concentration.

The colonies were counted after $24 \mathrm{hr}$ incubation. $\bigcirc, w$ type colony;,$y$ type colony. For other conditions, see text. 
colonies were not found at RoF concentrations of more than $2 \mu \mathrm{g} / \mathrm{ml}$, whereas $y$ type colonies appeared even at the concentration of $1000 \mu \mathrm{g} / \mathrm{ml}$. Therefore, the order of RoFresistance was found to be $y>w>$ parent strain.

Flavin production of RoF-resistant strains of $S$. aureus

The agar and liquid media which were inoculated with $y$ type colonies were strongly fluorescent under UV light. The RF in the culture filtrate was identified as free RF by the two systems of thin layer chromatography described in Materials AND Methods. Though the resistant bacterial cells were thought to contain FMN and FAD, identification of the phosphorylated RFs in cells was not attempted, because their RF contents were nearly the same as in the parent, as shown in

\section{Table I. Flavin Produced in Culture Broth by the Parent and the RoF- RESISTANT STRAINS OF $S$. aureus}

The strains were incubated in $5.0 \mathrm{ml}$ of culture fluid in test tubes (diameter $15 \mathrm{~mm}$ ). The RF contents in the table are not the actual but the calculated values, i.e., the amount of RF in $1.0 \mathrm{ml}$ of culture broth itself, or in the bacterial cells or in the culture filtrate obtained from $1.0 \mathrm{ml}$ of the culture broth, whose $\mathrm{OD}_{620}$ is normalized to 1.0 .

\begin{tabular}{|c|c|c|c|}
\hline Strain & $\begin{array}{c}\text { Culture } \\
\text { broth }\end{array}$ & $\begin{array}{c}\text { Bacterial } \\
\text { cells }\end{array}$ & $\begin{array}{l}\text { Culture } \\
\text { filtrate }\end{array}$ \\
\hline Parent & $\begin{array}{l}0.043^{*} \\
\pm 0.0142^{* *} \\
\quad(25)\end{array}$ & $\begin{array}{c}0.034 \\
\pm 0.0019 \\
(6)\end{array}$ & $\begin{array}{l}0.016 \\
\pm 0.0155 \\
\quad(6)\end{array}$ \\
\hline $\begin{array}{c}\text { Resistant } \\
y\end{array}$ & $\begin{array}{l}0.646 \\
\pm 0.1094 \\
\quad(25)\end{array}$ & $\begin{array}{l}0.025 \\
\pm 0.113 \\
\quad(6)\end{array}$ & $\begin{array}{l}0.693 \\
\pm 0.0470 \\
\quad(6)\end{array}$ \\
\hline$w$ & $\begin{array}{l}0.087 \\
\pm 0.0163 \\
\quad(26)\end{array}$ & $\begin{array}{l}0.036 \\
\pm 0.0020 \\
(6)\end{array}$ & $\begin{array}{l}0.040 \\
\pm 0.0158 \\
\quad(6)\end{array}$ \\
\hline$s$ & $\begin{array}{l}0.048 \\
\pm 0.0144 \\
\quad(30)\end{array}$ & $\begin{array}{l}0.035 \\
\pm 0.0023 \\
\quad(12)\end{array}$ & $\begin{array}{l}0.0084 \\
\pm 0.0144 \\
(12)\end{array}$ \\
\hline
\end{tabular}

* $\mathrm{RF} \mu \mathrm{g} / \mathrm{ml}$ culture broth/$/ \mathrm{OD}_{620}, 1.0$ growth.

** Mean and standard deviation.

Figures in parentheses are numbers of samples.
Table I.

The RF produced in the culture broth of the resistant and parent strains was determined as described in Materials and Methods. The results are shown in Table I. The amounts produced in whole culture broth of the resistant strains were the highest for the $y$ type and the lowest for the $s$ type. The latter was nearly the same as that of the parent. The contents in the cells of the four types were almost the same. Therefore, the RF overproduced by the resistant strains was secreted into the culture filtrates, and the order of amounts of RF overproduced was the same as the decreasing order of the resistance, i.e., $y>w>s=$ parent.

It would be interesting to assume that the $y$ and $w$ strains are resistant to $\mathrm{RoF}$ by producing sufficient amounts of RF to compete with RoF. $^{3)}$ The overproduction of an essential metabolite in a resistant bacterium in response to an antibacterial substance is already known: for example, the overproduction of $p$-aminobenzoic acid by the sulfonamide-resistant strains of $S$. aureus was reported. ${ }^{8)}$ The overproduction of RF by RoF-resistant strains is analogous to this. However, the appearent resistance of the $s$ type was different, because it did not overproduce RF. Such a mechanism can be explained by a number of speculations. ${ }^{9)}$ For example, it may survive by (1) conversion of RoF to an inactive derivative by enzyme(s) produced by the resistant cells, (2) modification of the RoF-sensitive site, including formation of enzyme(s) insensitive to Rof, (3) loss of cell permeability of RoF, (4) increasing levels of the enzyme inhibited by RoF, (5) enhancement of an alternative metabolic route bypassing the inhibited pathway, (6) decreased requirement for a product of the inhibited metabolic system, or (7) increased concentration of a metabolite that antagonizes RoF. The last mechanisms would be that of $y$ and $w$ type resistant strains. In the case of the $s$ type, the characteristic was that it appeared after the growth of the $y$ type which overproduces RF. It would be interesting to speculate that the $s$ type may survive in the presence of RoF by efficient use of RF which was produced by the 
$y$ and $w$ strains. Of course, to verify these hypotheses, more quantitative experiments must be done.

RoF-resistant strains of B. pumilus IFO 12092 and IFO 3813 and $R F$ production

RoF-resistant strains of $B$. pumilus IFO 12092 and 3813 were isolated from agar plates (RoF, $20 \mu \mathrm{g} / \mathrm{ml}$ ). Their frequencies of ap-

\section{Table II. Flavin Produced in Culture \\ Broth by the Parent and the RoF- RESISTANT STRAINS OF B. pumilus IFO 12092, 3813, AND B. subtilis $\mathrm{HW}$}

Conditions were the same as those in Table I

\begin{tabular}{cccc}
\hline Strain & $\begin{array}{c}\text { Culture } \\
\text { broth }\end{array}$ & $\begin{array}{c}\text { Bacterial } \\
\text { cells }\end{array}$ & $\begin{array}{l}\text { Culture } \\
\text { filtrate }\end{array}$ \\
\hline
\end{tabular}

IFO 12092
Parent

$\begin{array}{ccc}0.116^{*} & 0.058 & 0.067 \\ \pm 0.0280^{* *} & \pm 0.0054 & \pm 0.0222 \\ (28) & (6) & (6) \\ 0.575 & 0.077 & 0.503 \\ \pm 0.1070 & \pm 0.0036 & \pm 0.0199 \\ (36) & (6) & (6)\end{array}$

IFO 3813

$\begin{array}{cccc}\text { Parent } & 0.162 & 0.050 & 0.075 \\ & \pm 0.0810 & \pm 0.0030 & \pm 0.0274 \\ & (32) & (8) & (12) \\ \text { Resistant } & 0.536 & 0.058 & 0.655 \\ & \pm 0.1903 & \pm 0.0127 & \pm 0.2013 \\ & (28) & (6) & (6)\end{array}$

HW

Parent

$$
\begin{aligned}
& 0.421 \\
& \pm 0.0697 \\
& 0.075 \\
& \pm 0.0083 \\
& 0.316 \\
& \pm 0.0401 \\
& \text { (6) } \\
& 0.065 \\
& \pm 0.0040 \\
& 0.355 \\
& \begin{array}{r} 
\pm 0.0556 \\
(24)
\end{array} \\
& \text { (6) } \\
& \begin{array}{llll}
\text { fp } & 10.04 & 0.081 & 10.30
\end{array} \\
& \pm 1.808 \\
& \pm 0.0094 \\
& \text { (6) (6) } \\
& \text { fn } \quad 0.434 \\
& \pm 0.072 \\
& 0.078 \\
& 0.306 \\
& \pm 0.0168 \\
& \text { (6) } \\
& \pm 0.0512
\end{aligned}
$$

pearance were about $2 \times 10^{-3}$ and $2.5 \times 10^{-6}$, respectively. The RF produced in each fraction of culture broth of the resistant and the parent strains is shown in Table II. It was found that the resistant strains of both bacilli formed more RF than the parent, and RF was overproduced in the culture filtrate as for Staphylococcus.

\section{RoF-resistant strains of $B$. subtilis $H W$}

$B$. subtilis $H W$ was fairly different in some respects from B. pumilus IFO 12092 and IFO 3813. The HW strain formed two types of colony, the smooth (S) and rough (R) types on agar plates. This strain was more resistant to RoF than other bacteria tested here, especially the $\mathrm{R}$ type (Fig. 2), i.e., on an agar plate containing $2 \mu \mathrm{g} R \mathrm{RF} / \mathrm{ml}$, the survival rate of the $\mathrm{R}$ type was nearly 1 , and that of the $\mathrm{S}$ type 0.5 (average values in Fig. 2), in contrast to those of $S$. aureus, and $B$. pumilus IFO 12092 and 3813 , which were $7 \times 10^{-6}, 5 \times$ $10^{-3}$ and $5 \times 10^{-6}$, respectively.

Flavin production of RoF-resistant strains of $B$. subtilis $\mathrm{HW}$

RoF-resistant strains of the bacillus were isolated from agar plates containing $100 \mu \mathrm{g}$

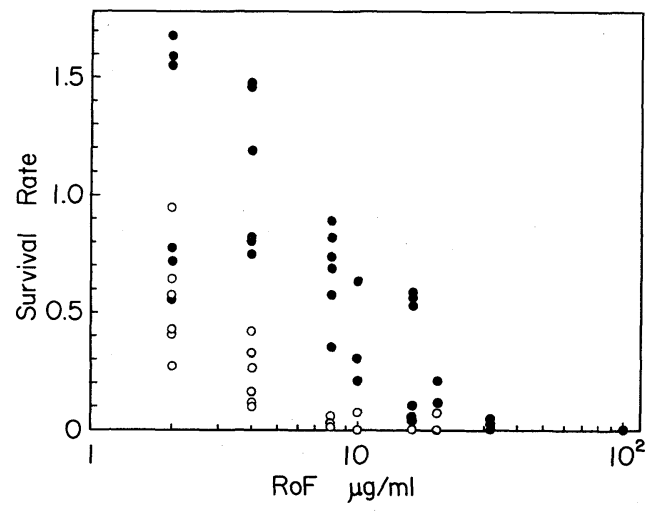

FIG. 2. Survival Rates of S and R Types of B. subtilis HW on RoF-containing Media.

A suspension of the $\mathrm{S}$ or $\mathrm{R}$ type bacterium was dispersed on agar medium, and the colonies were counted after $24 \mathrm{hr}$ incubation. The ratio of colony number on RoFcontaining medium to that on control medium (no RoF), i.e., survival rate, was plotted against RoF concentration. $\mathrm{O}, \mathrm{S}$ type; $\mathbf{O} \mathrm{R}$ type. For other conditions, see text.

* $\quad \mathrm{RF} \mu \mathrm{g} / \mathrm{ml}$ culture broth/OD $\mathrm{OD}_{620}, 1.0$ growth

-** Mean and standard deviation.

Figures in parentheses are numbers of samples. 
$\mathrm{RoF} / \mathrm{ml}$, and the frequency of appearance was about $1 \times 10^{-3}$. The RF produced in the culture broth of the parent and the resistant strains was assayed as described above (Table II).

The RoF-resistant strains were classified into two types: One ( $f p$ type) formed an unexpectedly large amount of RF, about 30 times as much as the parent, and the other ( $f n$ type) formed the same amount of RF as the parent. The ratio of appearance of $f p$ to that of the $f n$ type was about 2 .

The RF overproduced by the $f p$ type was found in the culture filtrate and not in the cells. The RF in the culture filtrate was free RF, and no phosphorylated flavin was found. The situation was just the same as for the staphylococcus, and the other two bacilli.

It is interesting that the colonies of the $f p$ type were the $\mathrm{R}$ type and those of $f n$ both the $\mathrm{R}$ and $\mathrm{S}$ types. However, the relations between the mechanisms in the RoF-resistance, RF production and colony types are not yet known.

\section{Hereditary stability of RF-productivity}

Hereditary stability is important for practical use of the foregoing strains in preparing $\mathrm{RF}$, though those strains are not useful because of the low productivity compared with that of Eremothecium ashbyii. However, since there is a possibility of inducing strains of higher RF-productivity useful for producing $\mathrm{RF}$, such a hereditary property in the $f p$ type was examined.

A colony of the $f p$ type, which was reselected on a RoF agar plate $(50 \mu \mathrm{g} / \mathrm{ml})$, was successively transferred five times to new slants (no RoF). From the original single colony on the RoF agar before subculture, a plate culture was carried out on the agar medium without RoF, and several colonies that grew on it were isolated and put into liquid medium, and then incubated. At the early stationary phase, the RF production in every tube was determined. Also from the fifth subcultured slant on no RoF agar, plate cultures, isolation of colonies into liquid medium and cultivation were done.
The RF-productivity of the original colony was assayed and found to be $19.5 \pm 1.60 \mu \mathrm{g} / \mathrm{ml}$ culture broth/ $\mathrm{OD}_{620}, 1.0$ (results from 24 colonies), and that of the fifth culture was $18.4 \pm 0.77$ (from 5 colonies). Therefore, the RF-productivity persisted at least for five successive subcultures.

It was assumed that in successive subcultures, the presence of RoF may be favorable for retaining RF-productivity. Therefore, the above-mentioned original colony was successively transferred five times to RoFcontaining slants $(5 \mu \mathrm{g} / \mathrm{ml})$. The RFproductivity of the last slant was measured as described above. The result was $18.9 \pm 2.75 \mu \mathrm{g} /$ $\mathrm{ml}$ culture broth/ $\mathrm{OD}_{620}, 1.0$ (from 5 colonies). Accordingly, no significant difference could be seen between the RF-productivity of the two groups. In another experiment, such productivity by colonies subcultured successively 10 times on slants (no RoF) was $26.0 \pm 7.79$ (44 colonies) and that of colonies on RoFcontaining slants $25.0 \pm 14.30$ (39 colonies), showing also no difference. Therefore, there was no advantage in adding RoF to the culture medium for preservation.

Since the highest RF-productivity of the $f p$ type was $58.8 \mu \mathrm{g} / \mathrm{ml}$ culture broth/OD ${ }_{620}, 1.0$ (actual concentration was about $24 \mu \mathrm{g} / \mathrm{ml}$ ), it is not useful at present for producing $\mathrm{RF}$ as described above. However, there is still a possibility of selecting higher RF-producing strains on RoF medium, especially that containing a mutagenic agent and of selecting a culture medium for higher growth. Such a strain may also be useful in genetic technology for producing RF. Moreover, a similar technique employing antagonists of other vitamins may be applicable to induction of various vitaminproducing mutants, which is practically useful for the vitamin industry. Methods using bacteria would be superior to those using molds in the speed of production and growth.

Acknowledgment. The authors thank Professor J. Kawamata of the Research Institute for Microbial Diseases, Osaka University for donating the strains of bacteria. 


\section{REFERENCES}

1) S. Otani, M. Takatsu, M. Nakano, S. Kasai, R. Miura and K. Matsui, J. Antibiotics, 27, 88 (1974).

2) S. Kasai, R. Miura and K. Matsui, Bull. Chem. Soc. Jpn., 48, 2877 (1975).

3) S. Otani, "Flavins and Flavoproteins," ed. by T. P. Singer, Elsevier Scientific Publishing Co., Amsterdam, 1976, pp. 323 327.

4) S. Kasai, Y. Kubo, S. Yamanaka, T. Hirota, H. Sato, Y. Tsuzukida and K. Matsui, J. Nutr. Sci. Vitaminol., 24, 339 (1978).
5) S. Kasai, S. Yamanaka, H.-C. Wang and K. Matsui, J. Nutr. Sci. Vitaminol., 25, 289 (1979).

6) K. Yagi, "Methods of Biochemical Analysis," ed. by D. Glick, John Wiley \& Sons, New York, London, 1962, pp. $343 \sim 346$.

7) J. L. Crammer, Nature, 161, 349 (1948).

8) P. J. White and D. D. Woods, J. Gen. Microbiol., 40, 243 (1965).

9) T. J. Franklin and G. A. Snow, "Biochemistry of Antimicrobial Action," 2nd Ed., Chapman and Hall, London, 1975, pp. $188 \sim 206$. 